\title{
Quando o silêncio narra o que aconteceu: a morte em "To the Lighthouse"
}

\author{
When silence tells what happened: death in "To the Lighthouse" \\ ADRIANA MADEIRA COUTINHO (10 \\ Universidade Federal do Rio de Janeiro (UFRJ), Rio de Janeiro, RJ, Brasil.
}

\begin{abstract}
Resumo: Este artigo reflete sobre a condição humana e seu fim último, a morte, através do romance "To the Lighthouse", de Virginia Woolf, em que a narrativa se desenvolve na relação entre a vida e a morte. Nas três partes do romance os acontecimentos giram em torno da morte, não só da morte física mas também de uma morte simbólica. Para tanto são apontadas algumas observações sobre subjetivismo e realidade objetiva, sobre temporalidade e sobre a própria prosa moderna nas formulações de Erich Auerbach. Em uma perspectiva empírica a autora aproxima o romance de sua realidade concreta, desnuda a dificuldade da escrita após um evento traumático além de apresentar aos leitores a fragilidade humana diante do inesperado. O presente trabalho foi realizado com apoio da Coordenação de Aperfeiçoamento de Pessoal de Nível Superior - Brasil (CAPES) Código de Financiamento 001.

Palavras-chave: Virginia Woolf; Morte; Condição humana; Crítica literária.
\end{abstract}

\begin{abstract}
This article reflects on the human condition and its ultimate end, death, through Virginia Woolf's novel "To the Lighthouse," where the narrative unfolds in the relationship between life and death. In the three parts of the novel, events revolve around death, not only physical death but also a symbolic death. To this end, some observations on subjectivism and objective reality, on temporality, and on modern prose itself in the formulations of Erich Auerbach are pointed out. In an empirical perspective, the author brings the novel closer to its concrete reality, exposes the difficulty of writing after a traumatic event, as well as presenting the human frailty before the unexpected. This study was financed in part by the Coordenação de Aperfeiçoamento de Pessoal de Nível Superior - Brasil (CAPES) Finance Code 001.
\end{abstract}

Keywords: Virginia Woolf; Death; Human condition; Literary criticism. 


\section{O início de um fim}

Não saber qual é o começo talvez não seja uma boa forma de dar início a este artigo. Mas essa foi a melhor forma que encontrei para falar do que está contido no silêncio de quem queria calar por um longo tempo. $\mathrm{Na}$ introdução do Segundo Sexo, Simone de Beauvoir diz "hesitei muito tempo em escrever um livro sobre a mulher. O tema é irritante, principalmente para as mulheres." (2009). Gostaria que essa afirmação tivesse sido vencida, mas confesso que, mesmo para mim, feminista convicta, existe uma certa irritabilidade em ser tema de livro e uma falta de boa vontade em ficar reinventando espaços para falar de questões que abordam as mulheres e suas especificidades. Pode ser que eu esteja contaminada pelo absurdo, considerado por algumas (alguns), do que são as questões femininas, transformadas em "querelas" pela arrogância masculina (BEAUVOIR, 2009). Ainda assim, é o que serei capaz de fazer aqui!

Depois de "olhar" e "ouvir" nasce o "escrever" (CARDOSO DE OLIVEIRA, 1998). Me percebo no exato momento em que as palavras fogem, o escrever. Longe de mim querer buscar a palavra justa como Gustave Flaubert mas essa hora me fez pensar sobre algumas coisas que li, quando tive oportunidade de conhecer "Cartas Exemplares": "Que mania esquisita essa de passar sua vida a trabalhar dias sobre as palavras e a suar todo dia para arredondar períodos!" (FLAUBERT, 1993, p. 41).

Penso que não vou conseguir me desvencilhar da difícil condição em que se encontram aquelas (aqueles) que interpretam seus dados diante de uma pesquisa empírica, das (dos) que precisam relatar suas experiências nas delegacias para gerar boletins de ocorrências, das (dos) que repetem suas histórias, infinitas vezes, nas filas das instituições públicas para conseguir algum direito assegurado constitucionalmente, daquelas (daqueles) que precisam produzir relatórios ou trabalhos acadêmicos. Em todos esses casos, por mais leal que queiramos ser existe uma distância entre o que foi (o acontecimento) e as "formas que damos às nossas ideias" (STRATHERN, 2006, p. 45). Não, desta liberdade não reclamo, esta condição acaba por dar vazão à minha inventividade que está circunscrita aos limites compreensíveis do meu repertório de tradução e só diante dessa limitação poderão ser narrados. Sendo assim, algo sempre terá que ser forjado, inventado, tal como sugeriu Roy Wagner (2010) ou para não perder a possibilidade de referenciar uma mulher, nessas linhas iniciais, "é mais provável que a ficção contenha mais verdade do que o fato." (WOOLF, 2014, p. 13).

Durante meu trabalho de mestrado pude observar que nos estudos etnográficos, apesar de não ser esse o caso, tão importante quanto o conteúdo daquilo que se pretende estudar, o método tem especial destaque. A forma com a qual se chegou a determinadas conclusões, o lugar de onde se olhava para apreender determinada realidade podem modificar sobremaneira o conteúdo do objeto de estudo. Por mais honestidade que se use na apresentação dos dados, a própria interpretação deles passará pela capacidade de apreensão da (o) investigadora (investigador) e pelo mundo onde ela (ele) está inserida. A exposição do método e de como as informações foram obtidas possibilita à leitora (leitor), um conhecimento prévio sobre a (o) autora (autor) e as condições 
como esta (este) chegou a determinadas conclusões (MALINOWSKI, 1984). Nessa perspectiva, acho importante me localizar enquanto agente desse trabalho: feminista, mulher, mãe de dois filhos e uma filha, atualmente casada, filha de mãe e pai semianalfabetos, a primeira de três irmãs, a única que chegou à graduação. Depois disso, mestra em Direto e, atualmente, doutoranda.

Ingressei no doutorado em Março de 2018, foi um momento feliz da minha vida, disso eu lembro bem. Já no final do semestre, assisti, por acaso, uma aula da professora Flavia Trocoli ${ }^{1}$. Uma matéria que abordava algumas autoras mulheres em uma perspectiva psicanalítica, ela falava sobre o "To The Lighthouse" de Virginia Woolf, saí da aula impactada com a aparente frieza com que Virginia tratava a morte no romance. Os relatos da narrativa navegam na relação entre a vida e a morte. Nas três partes do romance, os acontecimentos giram em torno da morte, não só a morte física, mas também uma morte oculta e deixa para o leitor "descobrir o que é secreto e está oculto a partir de aspectos menosprezados ou ignorados, do refugo da observação" (FREUD, s/d, p.153). Em termos gerais, um romance em que parece não acontecer nada de importante, me trouxe um incômodo permanente.

\footnotetext{
Professora Adjunta da Universidade Federal do Rio de Janeiro. Possui graduação em Licenciatura em Letras pela Universidade Estadual de Campinas (1997), mestrado em Teoria e História Literária pela Universidade Estadual de Campinas (2000), doutorado em Teoria e História Literária pela Universidade Estadual de Campinas (2004) e Pós-Doutorado em Linguística (2004-2007) pela Universidade Estadual de Campinas. Tem experiência na área de Letras, com ênfase em Teoria Literária, Literatura Comparada e Literatura e Psicanálise. É membrofundador, e atualmente vice-coordenadora, do Centro de Pesquisas Outrarte - psicanálise entre ciência e arte, do IEL/UNICAMP.
}

Devo confessar que a morte para mim era um acontecimento distante, do qual tinha certeza mas pouca vivência. Meu último contato com ela, a morte, tinha sido há aproximadamente 15 anos, nascia meu terceiro filho e morria meu avô materno. Um contra censo, João, meu filho, nasceu em Junho, meu avô morreu em Junho. Bia, minha irmã mais nova, morreu em Junho, quinze anos mais tarde. Exatamente agora, neste dia, um ponto de encontro, quando Virginia Woolf me apresenta a plasticidade e a simplicidade da morte, eu me deparo com ela. Dia e aula que ficarão marcados em mim para o resto da vida. Mesmo passado algum tempo desse dia qualquer de Junho em que algumas (alguns) nascem e outras (os) morrem, parece muito difícil “explicar com palavras deste mundo, que partiu de mim um barco que também me levou" (PIZARNIK, 1962).

\section{Uma breve visita à obra}

O romance é divido em três partes: "The Window", "Time Passes" e "The Lighthouse". O início da obra é marcado por eventos que ocorrem em um único dia, Mr. e Mrs. Ramsay e seus oito filhos (James, Cam, Prue, Roger, Jasper, Andrew Nancy e Rose) recebem convidados, entre eles, Lily Briscoe, William Bankes, Augustus Carmichael, Charles Tansley, Paul Rayley e Minta Doyle, em sua casa nas ilhas Hébridas. A família simbolicamente representa a reprodução da vida, seus valores, questões individuais, disputas de poder, descontentamento. A Primeira Guerra Mundial traz para cena a violência como transformadora também da família.

A expectativa de James, o filho caçula, em ir ao farol marca o início da trama, expectativa quebrada quando o pai nega 
a possibilidade do passeio devido ao mau tempo. Daí em diante seguimos com o fluxo da memória de Mrs. Ramsay, que, sentada em sua cadeira, tricota uma meia para o filho do faroleiro. O ponto alto dessa primeira parte é o jantar, em que todos estão reunidos e nos é apresentada a consciência das reflexões feitas por cada um dos personagens. O fim acontece com Mr. Ramsay dizendo para sua esposa que ela não terminará de tricotar a meia, que simboliza a esperança da viagem ao farol. Mrs. Ramsay acaba por concordar com o marido que o tempo não estará bom para o passeio.

Na segunda parte, "Time Passes", são dez anos de acontecimentos narrados de forma rápida. Algumas metáforas demonstram o vazio desse momento, a descrição da casa abandonada, informações sobre as vidas dos personagens e notas rápidas a respeito das mortes de Mrs. Ramsay, Prue e Andrew. A notícia desses falecimentos aparece entre parênteses, uma forma de grifo do fato e ao mesmo tempo de secura sobre o acontecimento. Talvez a falta mesmo de palavras para traduzir a violência brutal da morte, uma linha entre parênteses, marcando a simplicidade e a constância da morte.

$\mathrm{Na}$ última parte, quem guia os acontecimentos é o pensamento da pintora Lily Briscoe. Somente depois do falecimento de Mrs. Ramsay é que ela é compreendida e tem a revelação que possibilita o término da pintura, iniciada há dez anos. Mr. Ramsay se redime de sua rispidez com a esposa, realizando o desejo da mulher de levar o filho James até o farol e percebendo que apenas na ausência é que pôde entender a verdadeira importância da esposa. Confortada com a possibilidade de Mr. Ramsay ter chegado ao farol, Lily encerra a pintura. Mas esse encerramento não marca só o final do livro ou o final do trabalho de Lily, marca a visão que ela buscava desde o início do livro e era impossibilitada de enxergar.

\section{Olhando da minha janela}

O título do romance, "To the Lighthouse", aponta tanto para uma referência ao sentimento passado, nostálgico dos verões nas Ilhas Hébridas, quanto para uma dedicatória, em relação ao futuro, vislumbrada pela viagem ao Farol pretendida pelo filho mais novo dos Ramsays.

Um dos marcadores temporais, na dualidade passado-presente, pode ser observado nas considerações feitas por Lily Briscoe com relação à tela que está pintando. A linha central que desenha no centro do quadro e, consequentemente, no fim da narrativa, separa dois tempos distintos permeados pelas diferentes formas que ela interpreta a memória dos verões nas Ilhas Hébridas.

Mrs. Ramsay, a protagonista, é por onde passa a carga espacial e também por onde são construídas as expressões psicológicas das personagens. Segundo Hussey (2000, p.42-43), os ecos e fragmentos de impressões e visões oferecidos pelos personagens filtram e descrevem as características da protagonista.

A primeira parte do romance está revestida de lirismo constituídos pela apreensão subjetiva das personagens, fazendo com que as impressões de Mrs. Ramsay sejam vistas como momentos capazes de perdurar. Assim, ao tratarmos de The Window, estamos tratando de Mrs. Ramsay. A mesma coisa acontece com The Lighthouse, terceira parte do romance, em que a perspectiva narrativa 
se volta para Mr. Ramsay, o patriarca. Em uma das possíveis tentativas de explicar as constantes interferências da subjetividade na realidade objetiva, o texto que se constrói emerge da fusão entre espaços ficcionais externos e internos.

O evento externo pode ser tratado como uma forma de moldar a realidade interna. Virginia Woolf cria uma cadeia de eventos que necessariamente não se prendem uns aos outros mas, como surgem de associações próximas, delimitam a conexão entre os acontecimentos.

A respeito dos estados de introspecção, Nunes (2003, p.19), afirma que o tempo interior compõe-se de momentos imprecisos, moldados "ao sabor de sentimentos e lembranças". É possível avaliar que existe uma certa ausência de ação no romance porque a carga subjetiva é que mantém o curso narrativo.

Para Benjamin (1983), o homem, durante sua vida, tem seu íntimo posto em movimento como uma sequência de imagens, as quais refletem seus pontos de vista, perceptíveis através de gestos e olhares que compõe o inesquecível. A lembrança transmite o acontecido de geração para geração; funda uma rede de histórias que, interligadas, formarão uma única no final. Muitos momentos presentes no romance não tinham importância em si, mas quando lembrados relacionam-se com eventos externos ou outras lembranças, sendo reconhecidos então posteriormente como "(...) depósitos de um sentido que nunca esteve presente, cujo presente significado é sempre reconstituído mais tarde, nachträglich, posteriormente, suplementarmente (...)" (DERRIDA, 2005, p. 200). Se a lembrança é a única forma de presentificar fatos, segundo Benjamim
(1983), o sentido da vida só se manifesta depois de sua morte.

Sendo as percepções que ficam guardadas na psique desconexas da realidade temporal objetiva, é preciso encontrar um método para uni-las. A divisão do vácuo entre passado e presente, entre o dentro e o fora e a estratégia para essa conexão está na última parte do livro. Não quero dizer com isso que "To the Lighthouse" se constitui de pedaços desconexos ou mesmo separados, o fluxo da narrativa estabelece o que Bergson (2006, p.51-5) denomina de continuum. Sua função está exatamente em estabelecer a simultaneidade entre realidades temporais. Cada continuum simultâneo possui uma duração que concretiza o tempo que cada momento interior possui. A duração pode ser definida, então, como memória. Provocador do escoamento das realidades calcadas no tempo, o continuum é a garantia do contato entre passado e presente. Considerando que "toda percepção já é memória" (BERGSON, 2006, p.53), a modificação de um acontecimento passado é seu mobilizador para a formação da memória.

A narrativa fica mais dinâmica na segunda parte do romance e nos traz a sensação de fluidez temporal, fazendo com que o tempo presente passe de forma não percebida. Em sua teorização sobre o tempo, Bergson (2006, p. 157-160) afirma que o ser humano prende-se com mais ênfase ao tempo vivido do que ao tempo real, pois valoriza as experiências, e tais experiências constituem sempre o resultado desse tempo vivido. Nesta parte do romance, a ausência é um marcador que caracteriza o enredo.

Na tentativa de dar ao texto um caráter ambivalente, a autora parece fazer o 
passado perpassar todo o texto. A diluição do passado mantém a presença mesmo ausente, depois da morte de Mrs. Ramsay. "Cristais de tempo", termo utilizado por Deleuze (2007, p.103), caracteriza o passado como tempo vivido, explicando que a cristalização do passado permite que tenhamos acesso a ele continuamente, mas fica sempre na qualificação de experiência vivida. Isso acontece de forma com que o presente consista em explicar situações vividas em outro momento e não como vivência plena, do próprio momento (momento presente).

Buscando se desprender do tempo vivido com Mrs. Ramsay, Lily trabalha na busca de um equilíbrio que unifica experiência e aprendizado. Sem qualquer interferência do julgamento dos Ramsay sobre sua obra, neste momento precisa arcar com a responsabilidade de, sozinha, tomar suas próprias decisões acerca daquilo que pretende fazer. Nesta parte da narrativa o tempo é simbólico, constituído de metáforas entre presente e passado, a presença da ausência de Mrs. Ramsay e as lembranças da família.

É possível trabalhar com a ideia de uma aproximação entre o quadro de Lily e a estrutura do romance, "dois blocos unidos por uma passagem" (BEER, 1996, p. 72). A ponte, o elo que faltava para o fim da obra de Lily, faz trazer à tona uma estrutura de "narrativa em abismo" ${ }^{2}$. Outro aspecto de negociação entre passado e presente seria o próprio passeio ao farol, pensado em um momento e realizado anos mais tarde, fazendo a ponte que unifica os dois tempos.

2 Termo francês "mise en abyme", utilizado pela primeira vez em 1893 pelo escritor André Gide para denominar as narrativas que contêm outras narrativas em seu interior (narrativas encaixadas).
Para Lily Briscoe, antes de ter a visão, seu quadro não consegue captar a aura daquilo que contempla, simbolizando uma mera reprodução do real. Essa constatação nos joga a crítica da autora às questões que fazem parte da construção de um novo objeto artístico e a forma como este se apresenta. Para Benjamim33, a aura "é uma figura singular, composta de elementos espaciais e temporais: a aparição única de uma coisa distante, por mais perto que ela esteja" (1994, p.170). Ela condensa o sentido de real, atribuído por uma classe fazedora e entendedora do fazer artístico. A possibilidade de reprodução de um objeto artístico representa o desmonte da aura e nesse processo de transformação é que consiste seu valor estético.

Baseado nisso, é possível dizer que a pintora destrói a aura, "retirar o objeto do seu invólucro, destruir sua aura, é a característica de uma forma de percepção cuja capacidade de captar o semelhante no mundo é tão aguda, que graças à reprodução ela consegue captá-lo até no fenômeno único" (BENJAMIN, 1994, p.170), quando consegue terminar sua obra.

Chego ao final dessas observações, percebendo que o tornar eterno na obra de arte e na vida é um processo de experiências e vivências que referenciam nosso estar no mundo. Não digo que seria necessário manter algo em essência, e sim fazer com que o tempo em que as coisas aconteceram, o tempo em que as pessoas viveram juntas tenha sentido, mesmo que esse seja atribuído posteriormente, tenha algum significado e influência, constituindo história (MAFFESOLI, 2003).

\footnotetext{
3 No ensaio "A obra de arte na era de sua reprodutibilidade técnica", publicado em 1955.
} 


\section{A ideia de uma totalidade que não é completude $^{4}$}

Para Leopoldo Waizbort as investigações de Erich Auerbach cartografam um mundo novo de feições do "realismo". Dessa forma, existe uma nova possibilidade de configurações diferentes de períodos e obras literárias, levando-nos a pensar outras configurações realistas (WAIZBORT, 2007, p. 12). A formatação engessada de escolas literárias reduz as estruturas que compõe a obra, enquanto o seu reconhecimento complexo, quando leva em consideração o mundo real, faz com que o crítico possa compreender a impossibilidade de um único realismo. Retirando os reducionismos de que a obra espelha o mundo real podemos ver através de suas nuances um mundo próprio atravessado pela realidade concreta.

Partindo de textos antigos da cultura greco-latina chegando até a modernidade, Mímeses compreende, entre outros e relevantes aspectos, uma abordagem original da questão da representação da realidade e do foco narrativo em obras emblemáticas da literatura ocidental.

De forma excepcional, com Erich Auerbach, a crítica literária no século XX experimentou enorme avanço quanto à metodologia de análise textual. Isso porque o filólogo, sociólogo e crítico soube, como poucos estudiosos da matéria, estabelecer uma profícua confluência da pesquisa histórica e filológica com a estilística para o esclarecimento da obra. Com sua erudição desenvolveu uma necessária e pertinente conexão entre filologia e literatura, permitindo avanços qualitativos em suas análises.

4 Conceito trabalho por Waizbort na obra de Antônio Candido.
Segundo João Adolfo Hansen, Auerbach levou a efeito modos de análise do realismo que representam categorias de pensamentos que formaram várias teorias de percepção e formação histórica:

A necessidade de construir textos autênticos se faz sentir quando um povo de alta civilização toma consciência dessa civilização e deseja preservar dos estragos do tempo as obras que Ihe constituem o patrimônio espiritual. (AUERBACH, 1976, p. 12).

Podemos considerar o fragmento acima como o reconhecimento da importância da crítica, adotando um estilo que aprofunda aspectos filológicos pertinentes ao trabalho de análise de questões relativas a obra, bem como uma necessidade de historiografia da literatura, duas perspectivas necessárias à compreensão dos autores(as).

Além de apontar a dimensão do trabalho de Auerbach como sociólogo da literatura, em um resumo, acerca da importância do trabalho desenvolvido pela autor de Mímeses, Waizbort afirma:

Desde cedo as pesquisas de Erich Auerbach foram tomadas, por seus contemporâneos, como contribuições à sociologia da literatura. Contudo, esse aspecto sempre foi considerado secundário, ofuscado pela empreitada gigantesca da sua escrita da história e por seus estudos filológicos. (WAIZBORT, 2004, p. 62).

\section{Virginia Woolf por Auerbach}

No último capítulo de Mimeses, Auerbach destaca da primeira parte do romance "To The Lighthouse", um trecho a ser analisado que ganhará o nome de "A Meia Marrom". Nele, apontará o processo 
entre as impressões subjetivas e objetivas da obra.

Mrs. Ramsay aparece cosendo uma meia marrom, que seria dada de presente ao filho do faroleiro, tomando como referência o comprimento da perna de James, o caçula que estava na expectativa de ir ao farol. Apesar da aparente insignificância do ato de coser a meia, o elemento externo, existe uma reflexão consciente de Mrs. Ramsay, o elemento subjetivo, e de outros personagens que estão fora da cena descrita, há referência a reflexões de personagens inomináveis, assim como impressões sobre Mrs. Ramsay que podem ser atribuídas à própria escritora.

O essencial a ser observado neste episódio é que um acontecimento exterior, de menor monta, proporciona fluxos de ideias que abandonam o momento presente e ficam subsumidos em outros estágios temporais. As representações da consciência não estão exatamente ligadas ao evento externo, essa tônica narrativa fará parte de novas características constitutivas dos processos modernos de construção da prosa narrativa. Não se trata de um subjetivismo particular, individual, mas desta reflexão de consciência na pluralidade dos sujeitos. Este novo processo de escrita que aparece no texto de Virginia Woolf desemboca em outras questões, como por exemplo a forma como ela trata o tempo. O tempo narrativo é impregnado por processos digressivos e não pelo tempo cronológico.

Auerbach tem a preocupação de elencar algumas características específicas na construção da prosa narrativa. No processo da escrita de Virginia Woolf o trabalho de estreitamento entre as realidades autêntica e objetiva, cortadas por impressões subjetivas, por meio de diferentes personagens, situações e temporalidade, é fundamental para construção desse novo elenco de fatores constitutivos dos processos modernos de narrativa.

Por meio de questionamentos subjetivos das diferentes personagens (inclusive da própria escritora como dá a entender o filólogo), Auerbach busca respostas sobre os enigmas não solucionados deixados pelo vazio, refletidos no sentimento de tristeza que abate Mrs. Ramsay quando soube da morte do pai de Marie, a criada suíça. É a partir daí que passa a pensar sobre a iminência da morte por meio do sentido das ações e das relações sociais, dos processos e estruturas de poder, do sentido da história, bem como das digressões de outras personagens, tais como Mr. Bankes e nas da própria autora, que não se coloca como narradora que conhece a personagem.

$\mathrm{Na}$ tentativa de compreender esses processos de tristeza, incerteza e vazio, que Auerbach vai chamar de "processo de dissolução", recorremos à história. Me parece justo referenciar essa debilidade social dos indivíduos, ou os apelos à subjetividade, no esfacelamento da ação exterior em detrimento das impressões subjetivas, na reflexão da consciência e na estratificação do tempo aos acontecimentos que marcam o período antes e o depois da Primeira Grande Guerra Mundial:

Nos anos de ao redor e após a Primeira Guerra Mundial, numa Europa demasiado rica em massas de pensamentos e em formas de vida descompensadas, insegura e grávida de desastre, escritores distinguidos pelo instinto e pela inteligência encontram um processo mediante o qual a realidade é dissolvida em múltiplos e multívocos reflexos da consciência (AUERBACH, 2015. p. 484). 
Ou seja, a nova forma do romance realista está, definitivamente, marcada por seu contexto histórico. A partir do século $\mathrm{XVI}$, por meio da expansão ultramarina e da conquista do Novo Mundo, da Reforma e da mudança de paradigma teocêntrico para o antropocêntrico, houve um alargamento de horizonte do ser humano. Com as revoluções burguesas e tecnológicas, já no século XIX, consolida-se a hegemonia do capitalismo. Nessa escalada o século XX é marcado pelo avanço das forças produtivas e tecnológicas, provocando uma tensão entre diferentes sociedades. As crises se intensificaram e deflagraram várias insurreições revolucionárias ligadas ao movimento socialista, como a Revolução Russa de outubro de 1917, Revolução Alemã de 1918 e 1923, Revolução Chinesa de 1911 e a Revolução Cubana de 1959, sem nos esquecermos da importantíssima revolta deflagrada na França a partir de maio de 1968. Além dessas convulsões sociais, também devemos constatar que o início do século XX foi marcado por disputas entre potências colonizadoras, mormente aquelas oriundas do neocolonialismo do século XIX, além de crises econômicas como a quebra da bolsa de New York em 1929. Todo este movimento tem seu desfecho nas Primeira e Segunda Guerra Mundiais.

Este é o cenário social em que está circunscrito a prosa moderna, em "To the Lighthouse" é percebido através dos esgotamentos emocionais que deixam marcas do vazio. Auerbach diz ser percebida a falta de consciência de Mrs. Ramsay de sua beleza física quando observamos a forma como ela se veste, como são seus atos, seus comportamentos, sua tristeza patente e latente; e o desencadeador externo para essa percepção está em mais uma cena aparentemente insignificante, quando Mrs. Ramsay levanta a cabeça e observa o estado da mobília da casa. Para Auerbach, é a partir desse movimento simples que se desencadeia um processo de rememoração consciente de Mrs. Ramsay, alargado através de camadas subjetivas. O autor assinala a intenção de Virginia Woolf trazer à tona a substância do real a partir de um ato qualquer, advindo do acaso, não podendo ser diferente, através, por exemplo, de uma experiência exterior integral que, neste momento, está marcada por uma vivência danificada, comprovada pelo vazio e falta de sentido, evidentes em Mrs. Ramsay que, por sua vez, são oriundos das crises da modernidade que arrebataram os indivíduos. Crises que nos deixaram como herança um sentimento de não identidade e de não reconhecimento.

A criação do novo método de escrita em Virginia Woolf pode ser atribuído à mudança de gravidade, confere-se menos importância aos grandes pontos cruciais externos e aos grandes golpes do destino, a crise da modernidade, na aposta ao acaso. A busca pela ordem e a interpretação da vida que surge dela própria, não cabendo neste contexto, representações das histórias de suas personagens, para Auerbach, isso acontece porque o instante qualquer é relativamente independente das ordens discutidas e vacilantes pelas quais os homens lutam e se desesperam. Sendo assim, em "To the Lighthouse" está refletida a dissolução do sentido da vida, a busca está no sentido das coisas, das relações sociais.

\section{Resumo dos factos}

Durante este trabalho me esforcei sobremaneira para tentar compreender 
a morte, digerir a morte, entender que é preciso morrer e resignar sabendo que esse é o fim último de quem vive.

Com Auerbach compreendi o realismo que atravessa o tempo cronológico das escolas literárias, o realismo enquanto realismos ou modalidades, já que a realidade não está fora da obra, mas nela mesma. Como também afirmou Cândido (2000), o externo torna-se interno. O atravessamento do contexto histórico, do próprio processo social transformado em material literário. A consequência última disso, é perceber que a crítica precisa, de alguma forma, analisar o contexto social e histórico. De outra forma, é o profundo conhecimento histórico e social embutido nas obras que permitiu Auerbach perceber as particularidades apresentadas de uma mesma faceta. Uma mediação entre obra e sociedade funda determinado realismo, que se modifica de acordo com o contexto e se transforma em um realismo particular.

\begin{abstract}
Deve-se supor que uma transformação na execução artística imitativa e nos seus objetos está conectada a uma transformação da visão de si humana e, além disso, a uma transformação correspondente do próprio ser humano e de sua estrutura social (AUERBACH, 1937b, p. 276).
\end{abstract}

Fundamentalmente entender que "o problema do realismo não está em suas metamorfoses, mas sim na afirmação do indivíduo como constante" (LIMA, 1986, p. 418). Auerbach levava em consideração um indivíduo intrinsecamente histórico. Um indivíduo que passa por transformações através da história, tornando-se único.

Chegando ao final, gostaria de explicitar minha empatia por Virginia Woolf, por isso, em breves linhas divido, nesta última parte, meu sentimento em relação a autora. No dia 12 de Junho de 2018, uma terça-feira, não precisava estar na universidade. Fui convidada para assistir uma leitura performática de um livro chamado "Ensaio de Voo"5 da Paloma Vidal, essa atividade aconteceria na parte da tarde. Registro aqui que, além de brilhante a leitura performática feita pela autora, o conteúdo do romance era uma conversa dela com a irmã que havia partido, o tempo da escrita era o tempo de duração do voo, em uma urgência em chegar a um determinado número de palavras, a autora também fazia uma brincadeira com a temporalidade, o tempo da escrita, o tempo de voo, o tempo vivido longe e perto da irmã.

Cheguei na universidade cedo e, como de costume, aproveitei o tempo ocioso assistindo uma aula sobre Virginia Woolf, como disse na introdução desse trabalho. A aula era sobre a morte em "To the Lighthouse" esse foi um detalhe que só compreendi no fim deste dia. É certo que os parênteses são curiosos, mas as poucas linhas que falam das mortes de personagens tão importantes me perturbaram mais:

[Mr. Ramsay, andando aos tropeços pelo corredor em certa manhã sombria, estendeu os braços, mas como Mrs. Ramsay morrera repentinamente na noite anterior, seus braços, embora estendidos, permaneceram vazios.] (p. 85)

Alguns estudiosos da obra de Virginia argumentam que The Lighthouse é uma

\footnotetext{
Publicado pela Editora Quelônio, o livro é impresso em tipografia num papel azul, as contracapas são ilustradas com desenhos de um desses manuais de voo que a gente acha preso no assento da frente toda vez que entra num avião. O livro já deixa de ser apenas palavras impressas, ele é um objeto sensorial que suscita memórias e todo um aparato imagético.
} 
espécie de negociação com o passado. A angústia de Lily ao retornar à casa vazia possivelmente traz à cena o estado de melancolia pelo qual passam os seres humanos, depois de um processo de luto. Quando algo importante é perdido, deixa um rastro de inconformidade com a perda ou a derrota e nos aproxima de uma espécie de rejeição do que sobrou. Tudo o que existe depois da perda fica em suspenso, meio sem sentido. $\mathrm{O}$ apego ao que está para além daquilo que foi perdido, apesar de dificultar o apagar da ausência presença, faz com que consigamos acordar no outro dia, tem sido assim comigo.

No dia em que me apaixonei por Virginia Woolf, que assisti à belíssima apresentação do livro de Paloma Vidal, uma terça-feira qualquer de uma semana qualquer, não tive tempo de me despedir, voltei para casa e ela já não estava lá ["sim; percebia que o degrau da sala de visitas estava vazio (...)"] (p. 126).

Antes que esse dia terminasse recebi a notícia de que minha irmã falecera. Vivi todos os momentos que precederam o atestar da morte e vivo, até agora, a dor de ter perdido para a morte uma pessoa tão especial. Vivo a infelicidade de ver pais que (sobre)vivem diante da perda de alguém que devia morrer depois deles. Em algum momento da nossa consciência histórica ficou registrado que a morte tinha um caminho para a colheita, uma certa linearidade cronológica. Que bobagem! A anarquia provocada pela morte precoce da minha irmã caçula, reforçou minhas convicções de que "tão logo o homem entra na vida já é velho o suficiente para morrer" (HEIDEGGER, 2017, p. 326).

Entendi, profundamente, as rasas linhas escritas por Virginia sobre a morte. A profundidade do sentimento é da or- dem do inominável. Virginia Woolf já tinha experiência de morte com a perda, especialmente a da mãe, e vinha perdendo a própria vida quando não conseguia mais administrar viver nesse mundo.

Por fim, tal qual Virginia, concordo que a escrita deva obedecer a formalidades, porque a mente que vaga pode falar de um lugar menos interessante ao seu leitor. Ao mesmo tempo "o fogo irregular deve estar lá; e, talvez, para se soltar, a pessoa deva começar por ser caótica" (WOOLF, 2014, p. 175). Nessa reflexão está contida uma crença que daqui da onde eu posso olhar, já enxergando o todo, consigo perceber o que não precisaria estar escrito mas, só rabiscando todas essas palavras consegui dar fim a este artigo.

\section{Referências}

AUERBACH, Erich. Mímeses: a representação da realidade na literatura ocidental. São Paulo: Perspectiva, 2015.

AUERBACH, Erich. Zur Technik der Frührenaissancenovelle in Italien und Frankreich. Heidelberg. 2. ed. Oakland: University of California Libraries, 1971.

BEAUVOIR, Simone. O Segundo sexo. 2. ed. Rio de Janeiro: Nova Fronteira, 2009. 2 v.

BEER, Gillian. Virginia Woolf: The Common Ground. Michigan: University of Michigan Press, 1996.

BENJAMIN, Walter. O narrador. In: TEXTOS escolhidos. Rio de Janeiro: Victor Civita, 1983.

BENJAMIN, Walter. Magia e técnica, arte e política: ensaios sobre literatura e história da cultura. São Paulo: Brasiliense, 1994.

BERGSON, Henri. Matéria e memória: ensaio sobre a relação do corpo com o espírito. São Paulo: Martins Fontes, 2006.

BERGSON, Henri. Duração e simultaneidade. Trad. Claudia Berliner. São Paulo: Martins Fontes, 2006. 
CANDIDO, Antonio. Textos de Intervenção. Seleção, apresentação e notas de Vinícius Dantas. São Paulo: Duas Cidades, Ed. 34, 2002.

CANDIDO, Antonio. Literatura e sociedade. São Paulo: T. A. Queiroz/Publifolha, 2000.

DELEUZE, Gilles. A imagem-tempo. Trad. Eloisa A. Ribeiro. São Paulo: Brasiliense, 2007.

DERRIDA, J. A escritura e a diferença. São Paulo: Perspectiva, 2005.

FLAUBERT, Gustavo. Cartas Exemplares. Rio de Janeiro: Imago, 1993.

FREUD, S. Textos essenciais sobre Literatura, Arte e Psicanálise. Organização J. Basto e S. Basto. Lisboa: Europa-América, 1994.

HANSEN, José Adolfo. Floema. Caderno de Teoria e História Literária, Vitória da Conquista, v. 1, 2006.

HEIDEGGER, Martin. Ser e o Tempo. 10. ed. Rio de Janeiro: Vozes, 2017.

HUSSEY, Mark. How Should One Read a Screen? In: CAUGHIE, Pamela L. (ed.). Virginia Woolf in The Age of Mechanical Reproduction. New York: Garland Publishing Inc., 2000.

MAFFESOLI, Michel. O instante eterno: $O$ retorno do trágico nas sociedades pós-modernas. Trad. Rogério de Almeida e Alexandre Dias. São Paulo: Zouk, 2003. https://doi.org/10.5585/cpg. v15n0.6864

MALINOWSKI, Bronislaw. Os Argonautas do Pacífico Ocidental: um relato do empreendimento e da aventura dos nativos nos arquipélagos da Nova Guiné Melanésia. São Paulo: Abril, 1984.

MEPHAM, John. Figures of Desire: Narration and Fiction in To the Lighthouse. In: REID, Sue (ed.). Mrs Dalloway and To the Lighthouse: contemporary critical essays. London: Macmillan Press, 1993.

NUNES Rui. Ofícios de vésperas. Lisboa: Relógio D'água, 2007.

OLIVEIRA, Luis Roberto Cardoso de. Direito Legal e insulto moral: dilemas da cidadania no Brasil, Quebec e EUA. Rio de Janeiro: Relume Dumará, 1998.
PEDRÃO, Raquel Dommarco. O 'Ensaio de Voo' de Paloma Vidal: Editora Quelônio dá corpo e voz a texto inusitado. 2018. Disponível em: https://wsimag.com/pt/cultura/35284-o-ensaiode-voo-de-paloma-vidal. Acesso em: 24 ago. 2018. https://doi.org/10.11606/d.3.2017.tde11042017-143957

PIZARNIK, Alejandra. Arvore de Diana. Belo Horizonte: Relicário, 1962.

STRATHERN, Marilyn. O Gênero da dádiva: problemas com as mulheres e problemas com a sociedade na Melanésia. Campinas: Editora da Unicamp, 2006.

WAGNER, Roy. A invenção da Cultura. São Paulo: Cosac Naify, 2010.

WAIZBORT, Leonardo. Erich Auerbach sociólogo. Tempo Social, São Paulo, v. 16, n. 1, p.61-91, jun. 2004. Disponível em: http://www.scielo.br/ pdf/ts/v16n1/v16n1a04.pdf. Acesso em: 22 ago. 2018. https://doi.org/10.1590/s0103-20702004 000100004

WAIZBORT, Leopoldo. A passagem do três ao um: crítica literária, sociologia, filologia. São Paulo: Cosac Naify, 2007.

WALKER, David. Andre Gide. London: Macmillan, 1990.

WOOLF Virginia. To The Lighthouse. London: Penguin Books, 1992.

Recebido em: 04/12/2018

Aceito em: 10/03/2019

Publicado em: 00/05/2019

\section{Autora:}

ADRIANA MADEIRA COUTINHO

Doutoranda em Ciência da Literatura pela UFRJ, Mestra em Direito pela Universidade Católica de Petrópolis, graduada em Letras pela Universidade Católica de Petrópolis, bolsista Capes. Orcid: https://orcid.org/0000-0001-9626-1050

E-mail: madeiracoutinho@gmail.com 